\title{
Inquiry Based on Evidence and its Practices in Two Healthcare Facilities of Bujumbura
}

\author{
Emmanuel Gasaba', Jean Paul Nshimiyimana', Le Beni Bugingo', Ismaël Twiyubare', \\ Marie Jeanine Ndayishimiye1, Jonathan Niciza1, Emmanuel Ndarusanze1, \\ Clovis Ntahondahurira1, Edouard Niyongabo ${ }^{1,2}$
}

${ }^{1}$ Faculty of Health Sciences, Hope Africa University, Bujumbura, Burundi

${ }^{2}$ Department of Public Health Sciences, National Institute of Public Health, Bujumbura, Burundi

Email: niyongaboedouard@gmail.com

How to cite this paper: Gasaba, E., Nshimiyimana, J.P., Bugingo, L.B., Twiyubare, I., Ndayishimiye, M.J., Niciza, J., Ndarusanze, E., Ntahondahurira, C. and Niyongabo, E. (2021) Inquiry Based on Evidence and its Practices in Two Healthcare Facilities of Bujumbura. Open Journal of Nursing, 11, 170-183.

https://doi.org/10.4236/ojn.2021.113016

Received: February 17, 2021

Accepted: March 23, 2021

Published: March 26, 2021

Copyright () 2021 by author(s) and Scientific Research Publishing Inc. This work is licensed under the Creative Commons Attribution International License (CC BY 4.0).

http://creativecommons.org/licenses/by/4.0/

\begin{abstract}
Background: Inquiry evidence-based practice (IBP) improves healthcare quality, reliability, and patient outcomes as well as reduces variations in care and costs. IBP and its practice in health care promote also many advantages, such as improvements of practices based on the attitudes and cognitive ideas. This study aims to assess the inquiry based on evidence (IBP) and its practices in two Health Care Facilities (HCFs) of Bujumbura to help the practitioners to understand its importance. Methods: A cross-sectional study design was used to analyze the importance of IBP and its practice in these two hospitals. The probability-sampling technique was used also to select 104 nurses from the Military Hospital of Kamenge and 55 nurses from the Van Norman Clinic. A questionnaire was used to collect data with two mains components, demographic data and knowledge and attitudes addressing the following parameters: evidence practice during inquiry, nursing theory, current analysis in nursing care oriented the evidence, prioritization of care, rational diagnostic, monitoring and assessment. Results: The findings from this study revealed a poor knowledge and attitude among participants towards Inquiry Based Practice. In all variables, participants were scoring less than $10 \%$. However, majority of participants (76.5\%) know the indicators of patients' satisfaction with nursing interventions through survey-based practice and $74.1 \%$ argued to analyze their information collected. Conclusion: This study revealed a weak awareness on IBP and its importance during nursing practice among participants as for almost all variables, participants were scoring less than $10 \%$, except for the indicators of patients' satisfaction with nursing interventions through survey-based practice (76.5\%). Therefore, in-service training and curriculum revision had been highlighted and recommended another to provide the best rational diagnosis and achieve the patient's outcomes.
\end{abstract}




\section{Keywords}

Inquiry Evidence-Based Practice, Evidence-Based Practice, Healthcare Facilities, Rational Diagnosis

\section{Introduction}

Inquiry evidence-based practice (IBP) improves healthcare quality, reliability, and patient outcomes as well as reduces variations in care and costs. Nurses and other healthcare providers who use this approach should take account the analysis oriented on the most recent healthcare research during the treatment. Its values enhance and build on the clinical proficiency, knowledge of the disease mechanisms, and pathophysiology.

\section{Background}

In Bujumbura, health care facilities (HCFs) receive many patients daily and most of them need advanced IBP according to their critical situation [1]. However, non-specific studies that have been carried out in all HCFs of Bujumbura, to show how the nurses implement the IBP during nursing care. Therefore, the IBP should be the key indicator for promoting nursing care based on the evidence. This study will help the practitioners to understand the important of IBP in health care system and will provide the contribution to improving the IBP in HCFs.

In developing countries, it is reported that there is lack of use of IBP resulting to no implementation of EBP in their practice. This is influenced by several factors such as institutional, interdisciplinary and nurses related factors. It was reported this later is limited to be integrated into nursing education and practices due to shortage of human and materiel resources [2].

In developed countries like Canada and France, factors that facilitate IBP in nursing care are the following: beliefs in the value and the ability to orient the analysis in nursing care. In addition, trained nurses who have skills oriented on the IBP are the most professionals that provide the orientation in developed countries for achieving the goal of IBP in HCFs [3].

The barriers related to the implementation of inquiry evidence-based practice in most HCFs are the following: time limitations, the organizational culture and philosophy. For IBP model, a patient is the center and orients the approach founded on independent scientific research, clinical expertise and patient experiences [4].

Therefore, IBP and its practice in health care promote many advantages, such as improvements of practices based on the attitudes and cognitive ideas. Its organizations need to be understood on how nurses themselves use their capacity skills, oriented to the personal reflection, appraising evidence, clinical decision-making, for resolving issues of patients in other to get the best outcomes related to practical strategies, personal development planning and action learn- 
ing around structured reflection, which can help the nurses to develop the IBP. This study aims to assess the inquiry based on evidence (IBP) and its practices in two Health care facilities (HCFs) of Bujumbura and to help the practitioners to understand its importance.

\section{Conceptual Framework}

The Diffusion of Innovation Theory was chosen to guide this study. Innovation is an idea that is perceived as new by an individual, so while the concept of IBP is not new, it can still be considered an innovation. Roger's model describes five stages involved in the innovation-decision process. These stages are important to consider when planning implementation strategies for IBP. When making a decision of whether or not to implement an innovation, individual progresses through a process over time that involves these five stages: knowledge, persuasion, decision, implementation, and confirmation. The first step is knowledge, an awareness of the innovation and adequate knowledge of how it works. The next step, persuasion, builds on this mental understanding. The individual interacts with knowledge gained and forms an attitude that is either for or against adopting the innovation. After an attitude is formed, the individual begins to act in ways that lead up to a decision. The formal decision is made just before implementation. Typically, an individual will try out an idea before fully implementing it. In the final stage, a person will seek confirmation of his/her decision through action. This model demonstrates that adoption of an innovation is a process with several stages. Before an individual will adopt IBP practices, a formal decision must be made to implement IBP and knowledge and attitudes must precede the implementation. Research supports the significant role that awareness and attitudes play in the decision process of implementing IBP (Figure 1).

Some independent variables that influence negatively the IBP were no treatment of patients, bad healthcare delivery, and nurses who don't respect clinical rules, while its quality are influenced by qualities of healthcare and its strategies taken which will enhance the effective medical treatment cost and a better patient recovery (Figure 2).

\section{Methods}

The assessment of IBP was conducted in Burundi, in two HCFs of Bujumbura: Van Norman Clinic and Military Hospital of Kamenge located in the North District from November 2020 to January 2021. It was an observational study with an analytical character. A cross-sectional study design was used to analyze the importance of IBP and its practice in these two hospitals. The probability-sampling technique was used to select 104 nurses from the Military Hospital of Kamenge and 55 nurses from the Van Norman Clinic. All nurses having a contract with the HCFs were included in this study. In our study are excluded all nurses who don't have a contract with these HCFs and trainees. This study used Alain Bou- 
chard's formula to find the sample size in order to get 50 participants at Hospital Military of Kamenge, 35 participants at Van Norman Clinic. Authors intended to clarify the important of IBP in health care facilities; to identify the consequences of IBP not applied in healthcare and to suggest what can be done to promote IBP in HCFs. The data were collected by using the questionnaire established based on the following parameters: evidence practice during Inquiry, Nursing theory, current analysis in nursing care oriented the evidence, prioritization of care, rational diagnostic, monitoring and assessment. These latter were divided into two parts (identification and knowledge and attitudes).

A Statistical Package for Social Sciences was used to analyze and interpret data which were presented by tables and graphs. Ethical standards were observed, the intention was to respect the rights of the subjects in terms of the following principles: Self-determination, anonymity, confidentiality. As a result of this, we were able to maintain good collaboration with the participants. The validity and reliability of the questionnaire were not test in this study.

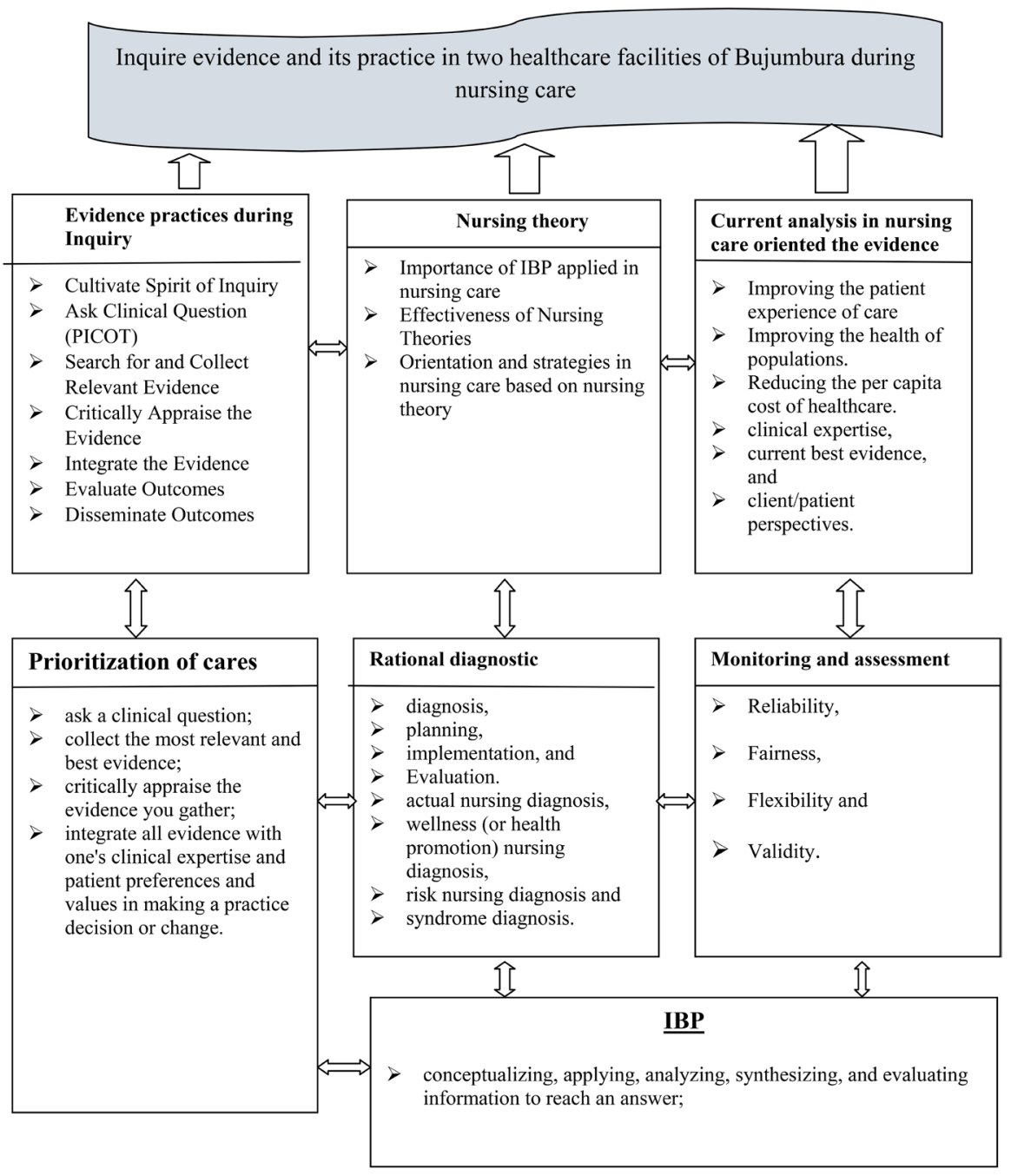

Figure 1. The steps of IBP in this study. 


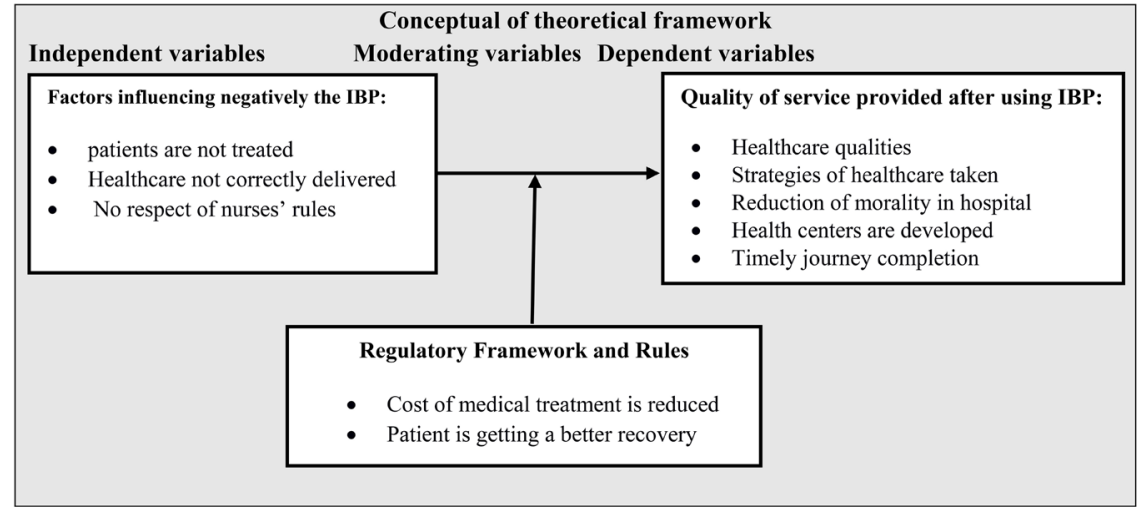

Figure 2. Conceptual of the theoretical framework [5].

Literature review was mostly reviewed on definitions and concepts of IBP, purpose and initiation of inquiries, Inquiry methods and process, steps of EBP, Strategies of searching and collect for best evidence in Inquiry, critically appraise the evidence, Benefits of IBP for Patients and its benefits for Health Care.

\section{Results}

The findings revealed that the age of participants ranged from $23-51$ years $(\bar{x}$ = 37). Majority of the participants were Female $(68.2 \%)$ and $31.8 \%$ were male. The Study level was represented with $49.4 \%, 37.6 \%, 9.4 \%$ and $3.5 \%$ respectively for the A2, A0, A3, masters. Regarding the period of nurse's experience, we noted that majority of them (65.9\%) were nurses with $1-4$ years on service, while others have 5 - 9 years, 10 - 14 years and more than 15 years $(22.4 \%, 8.2 \%$ and $3.5 \%$, respectively) (Table 1 ).

\section{Attitude and knowledge of the participants towards Inquiry Based Prac-} tice

This study revealed that a significant number of nurses do not know the importance of survey based on practice as 98.8 do not use it, $94 \%$ do not know the nursing orientation based on survey and $88 \%$ do not know nurse survey (Figure 3).

In this study majority of nurses do not know the steps related to the evidence practices in the context of nursing investigation, as the evidence practices during investigation revealed that (98.8\%) of nurses do not use PICOT, whilst $96.5 \%$ do not know the relevance and the critical evaluation of the evidence, $94.1 \%$ do not know the importance of information based on a survey during the implementation of nursing care and $92.9 \%$ do not know the existence of a spirit of investigation in the hospital for taking care of patient (Figure 4).

This study revealed also that $98.8 \%$ do not use theory during their nursing survey for practices based on a survey, $98 \%$ do not use theory to orient their interventions according the practices based on the survey, and $95.3 \%$ do not use nursing theory throughout their interventions and do not know the importance of IBP. 
Table 1. Demographic data.

\begin{tabular}{ccc}
\hline \multicolumn{1}{c}{ Characteristics } & & Frequency $(\mathrm{N}=85)$ \\
\hline \multirow{2}{*}{ Age } & Range & 23 years - 51 years \\
& Mean & 37 years \\
& Male & $31.8 \%$ \\
& Female & $68.2 \%$ \\
Study level of participants & $\mathrm{A}_{3}:$ & $9.4 \%$ \\
& $\mathrm{~A}_{2}:$ & $49.4 \%$ \\
& $\mathrm{~A}_{0}:$ & $37.6 \%$ \\
& Master: & $3.5 \%$ \\
Period of experiences (years) & $1-4:$ & $65.9 \%$ \\
& $5-9:$ & $22.4 \%$ \\
& $10-14:$ & $8.2 \%$ \\
& Over 15 & $3.5 \%$ \\
\hline
\end{tabular}

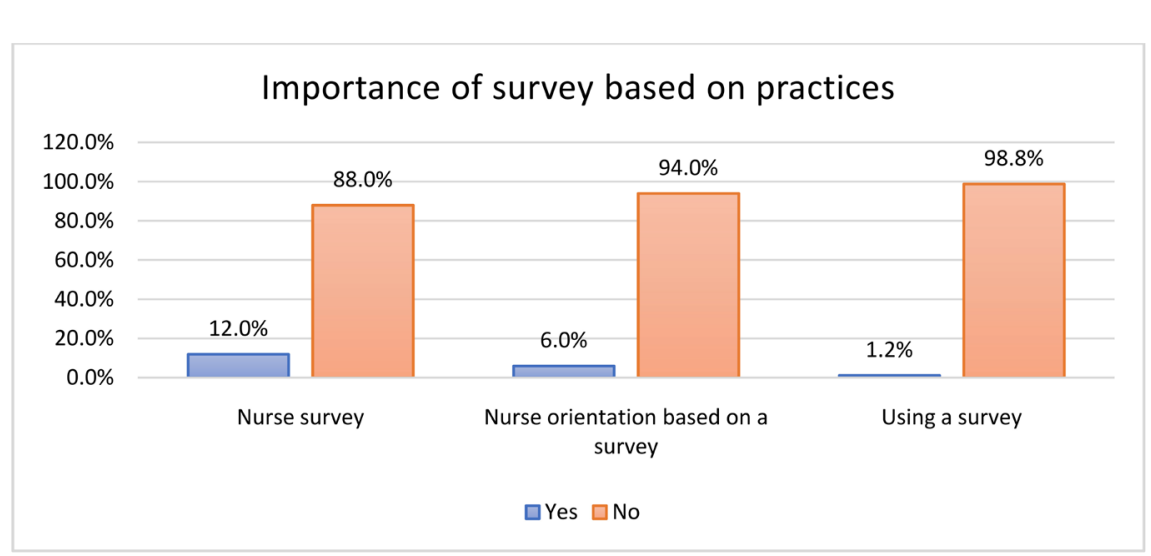

Figure 3. Importance of survey based on practices.

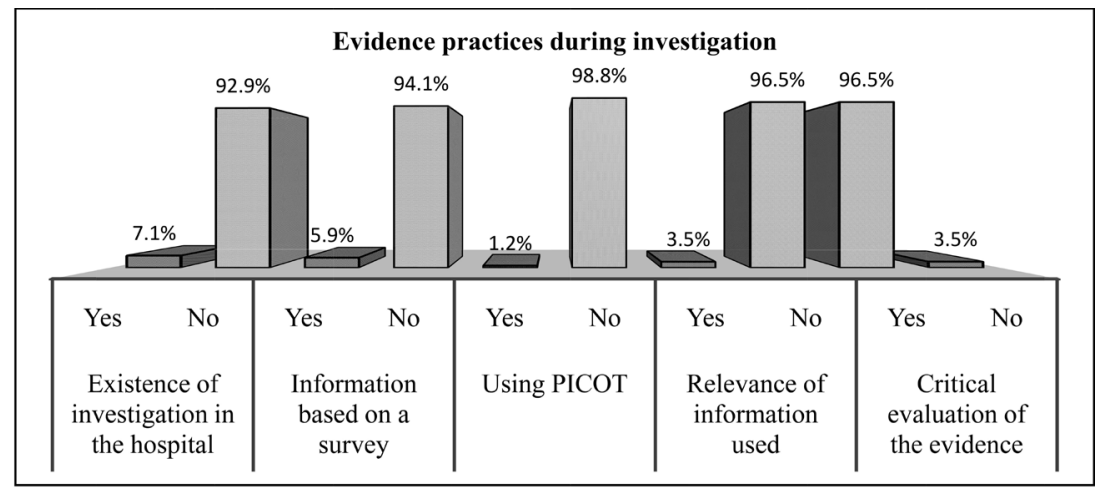

Figure 4. Evidence practices during investigation.

Concerning the prioritization of care, the study revealed that (97.6\%), (96.5\%), (95.3\%) and (15.3\%) were reported as the nurses who are not able to know the systematic collection of information, its priority, prioritizing information during reporting and consideration of patient values respectively. Only $84.7 \%$ argued that they consider the patient's preferences and values in decision making or practice based on evidence and clinical expertise (Figure 5).

The study showed that the majority of nurses (97.6\%) were not able to plan a 
rational diagnosis after nursing investigations, Moreover, rational diagnosis was not oriented according to the survey, nor the assessment wasn't considered before confirmation of the diagnosis while only $2.4 \%$ recognized those three steps (Table 2).

The study revealed that $76.5 \%, 70.6 \%, 52.9 \%$ were nurses who did not recognize the current analysis in nursing oriented based on evidence respectively with not respecting the stages of information collection, the place of situational analysis and experience in analyzing information. There is variability among these 3 steps because $47.1 \%, 29.4 \%$ and $23.5 \%$ have accepted to recognize experience in analyzing information, the place of situational analysis and respecting the stages of information collection respectively (Table 3 ).

The study showed that $76.5 \%$ know the indicators of patients' satisfaction with nursing interventions through survey-based practice, $74.1 \%$ argued to analyze their information collected and $45.9 \%$ only know the consequences of not following the practice based on a survey while $54.1 \%, 25.9 \%, 23.5 \%$ were nurses who knew satisfaction indicators, consequences of bad information and analysis of collected information respectively (Figure 6).

Only those with $1-4$ years $(3.5 \%)$ and $5-9$ years $(1.7 \%)$ know the use of theory in nursing and the direction of interventions according to the survey and they were able to know also the importance of IBP (2.4\% and $1.7 \%$ respectively). Only those with $1-9$ years $(1.7 \%)$ know the use of practices based on survey and $1.7 \%$ with 1 - 4 years were using nursing theories strategies (Table 4).

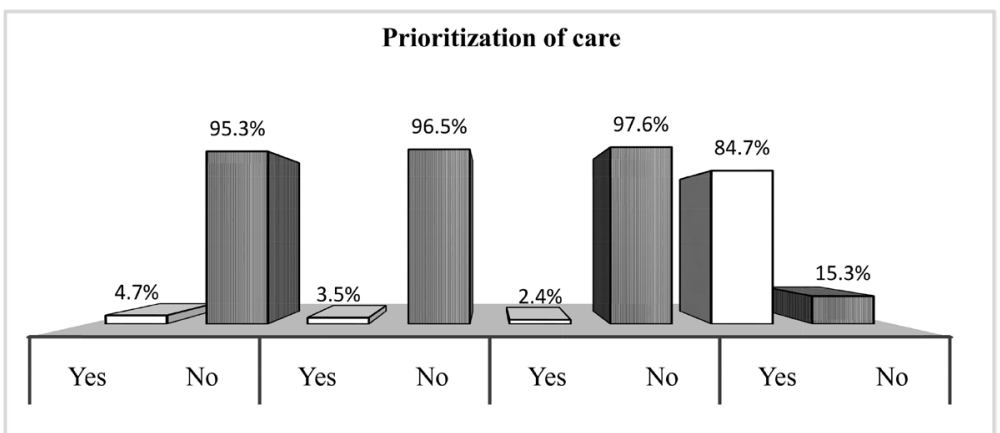

Figure 5. Prioritization of care.

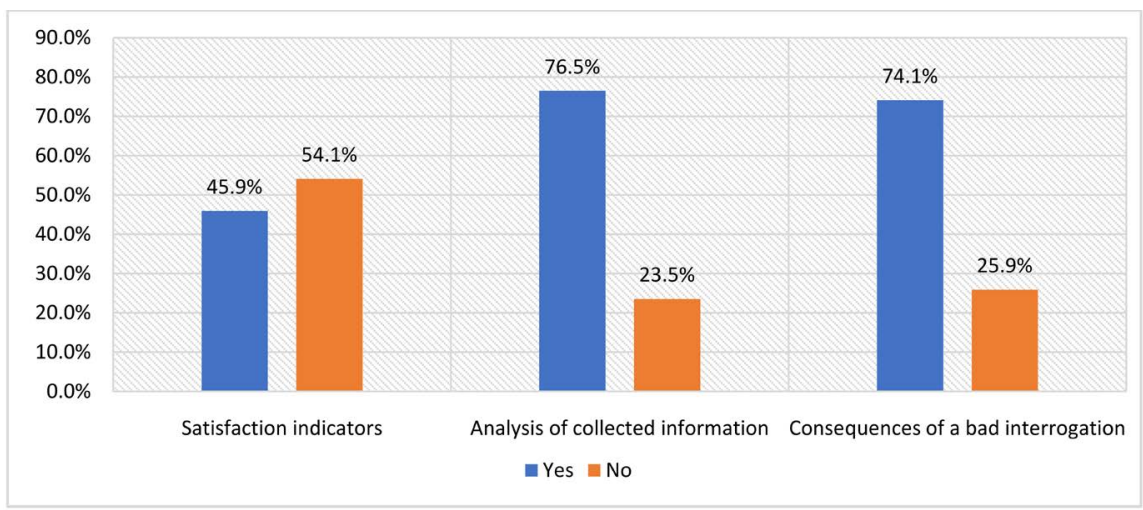

Figure 6. Monitoring and evaluation. 
Table 2. Rational diagnosis.

\begin{tabular}{ccc}
\hline \multirow{2}{*}{ Characteristics } & \multicolumn{2}{c}{ Frequency } \\
\cline { 2 - 3 } & Yes & No \\
\hline Planning a rational diagnosis & $2.4 \%$ & $97.6 \%$ \\
Orientation of rational diagnosis & $2.4 \%$ & $97.6 \%$ \\
Consideration of the assessment before confirmation diagnosis & $2.4 \%$ & $97.6 \%$ \\
\hline
\end{tabular}

Table 3. Current analysis in nursing-oriented evidence.

\begin{tabular}{ccc}
\hline \multirow{2}{*}{ Characteristics } & \multicolumn{2}{c}{ Frequency } \\
\cline { 2 - 3 } & Yes & No \\
\hline Experience in analyzing information & $47.1 \%$ & $52.9 \%$ \\
Respecting the stages of information collection & $23.5 \%$ & $76.5 \%$ \\
The place of situational analysis & $70.6 \%$ & $29.4 \%$ \\
\hline
\end{tabular}

Table 4. Comparison of participants' knowledge and attitude towards IBP and their Period of experience.

\begin{tabular}{|c|c|c|c|c|c|}
\hline & & \multicolumn{4}{|c|}{ Year of experience } \\
\hline & & $1-4$ & $5-9$ & $10-14$ & More than 15 \\
\hline \multirow{3}{*}{ Use of theories in nursing } & Yes & $3.5 \%$ & $1.7 \%$ & $0.0 \%$ & $0.0 \%$ \\
\hline & No & $40.2 \%$ & $16.7 \%$ & $5.2 \%$ & $3.2 \%$ \\
\hline & No response & $20.0 \%$ & $5.0 \%$ & $3.0 \%$ & $1.6 \%$ \\
\hline \multirow{3}{*}{$\begin{array}{l}\text { Direction of interventions } \\
\text { according to the survey }\end{array}$} & Yes & $3.5 \%$ & $1.7 \%$ & $0.0 \%$ & $0.0 \%$ \\
\hline & No & $42.2 \%$ & $7.7 \%$ & $6.2 \%$ & $2.0 \%$ \\
\hline & No response & $20.0 \%$ & $14.0 \%$ & $2.0 \%$ & $1.5 \%$ \\
\hline \multirow{4}{*}{ Importance of the IBP } & Yes & $2.4 \%$ & $1.7 \%$ & $0.0 \%$ & $0.0 \%$ \\
\hline & No & $40.5 \%$ & $11.7 \%$ & $6.2 \%$ & $2.5 \%$ \\
\hline & No response & $23.0 \%$ & $10.0 \%$ & $2.0 \%$ & $1.0 \%$ \\
\hline & Yes & $1.7 \%$ & $1.7 \%$ & $0.0 \%$ & $0.0 \%$ \\
\hline \multirow[t]{2}{*}{ Practices based on a survey } & No & $40.0 \%$ & $8.7 \%$ & $5.2 \%$ & $2.0 \%$ \\
\hline & No response & $24.2 \%$ & $12.0 \%$ & $3.0 \%$ & $1.5 \%$ \\
\hline \multirow{3}{*}{$\begin{array}{l}\text { Using nurse theory } \\
\text { for strategies }\end{array}$} & Yes & $1.7 \%$ & $0.0 \%$ & $0.0 \%$ & $0.0 \%$ \\
\hline & No & $42.0 \%$ & $12.0 \%$ & $6.0 \%$ & $2.5 \%$ \\
\hline & No response & $42.2 \%$ & $12.4 \%$ & $2.2 \%$ & $1.0 \%$ \\
\hline
\end{tabular}

\section{Discussion}

Some independent variables that influence negatively the IBP were highlighted such as no treatment of patients, bad healthcare delivery, and nurses who don't respect clinical rules, while its quality are influenced by qualities of healthcare and its strategies taken which will enhance the effectiveness of cost for medical 
treatment and a better patient recovery (Figure 1).

The Study findings revealed that the age of participants ranged from $23-51$ years $(\bar{x}=37)$. Majority of the participants were Female $(68.2 \%)$ and $31.8 \%$ were male. Majority of the participants had A2 level (secondary school diploma after 4 years of training) (49.4\%). This explained by the fact that previous skills in the country were oriented on the A2 level, whilst the Bachelor and master degree were introduced in 2009 and 2012 respectively. Regarding the year of nursing experience, we noted that majority (65.9\%) of nurses have an experience of 1 - 4 years, $22.4 \%$ of them have 5 - 9 years, $8.2 \%$ have 10 - 14 years whilst $3.5 \%$ have more than 15 years of experience in caring for patients, this revealed that in the past 10 years, there were lack of nurses as there were only the A2 and A3 level (secondary school certificate after 2 years of training), after the introduction of Bachelor level (A0) and masters level, the number of nurses have significantly increased $65.9 \%$ ( 1 - 4 years) and 22.4\% (5 - 9 years) (Table 1 ).

This study revealed that a significant number of nurses do not know the importance of survey based on practice as $98.8 \%$ do not use it, $94 \%$ do not know the nursing orientation based on survey and $88 \%$ do not know nurse survey (Figure 3). It is explained that these concepts are new, and the majority of them are not getting in service training on these latter. If the application is not carried out for helping the nurses of these two HCFs, this could be observed by the risk of increase rate of mortality, even increasing number of hospitalizations (Figure 1). In addition, the patients and the authorities of these two HCFs could spend a lot of budget. For reducing the high risk that could be recorded to the patients and for the site of HCF, it is important for the HCFs to train the nurses about the steps of IBP. For the university, it important to include in their curricula the information related to the steps of IBP. Beverly (2016) in his survey-based on practices has suggested that the nurses could contribute during the nursing in HCF by applying the research before providing the rational Diagnosis [6]. He continued by orienting his evidence by showing that considering these situations developed by that author, it is important for our study to suggest that the nurses and HCFs could apply in the daily activities the research on IBP in other to achieve the outcomes as the main target. Evidence-based practice is an approach that attempts to clarify how professionals or other decision-makers should make decisions by identifying evidence that there may be a practice and evaluating it according to its degree of scientific rigor. Its goal is to eliminate unhealthy or excessively risky practices for those with better results.

In this study majority of nurses (98.8\%) do not know the steps related to the evidence practices in the context of nursing investigation, as the evidence practices during investigation revealed that nurses do not use PICOT (Figure 4). However, a small number of participants (3\%) were the only ones whose study revealed to be knowing these steps which is explained by the fact that the nurses do not have skills in this information. The high risk could be observed to the patients with several complications caused by the lack of investigation that could 
result to the wrong rational diagnosis resulting to healthcare cost, elongated hospital stays (Figure 2). This concours with the Badoer's findings in her result who argue that the practice of evidence during the survey is an activity that nurses should practice after having a thorough knowledge of research, surveillance and interrogation techniques, survey-specific equipment as well as methods of collecting and preserving evidence [7]. Therefore; the five steps of investigation during IBP are important and could be applied in these HCFs. Inservice training for nurses about these five steps would be important so that they can have a good orientation in increasing their skills on these five steps. Moreover, Universities should include in their curricula this information and a committee in charge of monitoring and assessment of nursing skills should be putted by the government.

This study showed also that $98.8 \%$ do not use theory during their nursing survey for practices based on a survey, $98 \%$ do not use theory to orient their interventions according the practices based on the survey, and $95.3 \%$ do not use nursing theory throughout their interventions and do not know the importance of IBP. It could be explained by the fact that these nurses do not have any idea or information about the integration or the importance of using nursing theory into practice. Moreover, this study revealed that those with $1-4$ years $(3.5 \%)$ and 5 - 9 years $(1.7 \%)$ were the only ones to know the use of theory in nursing (Table 4). Meanwhile, this study revealed also that majority of the participants were A2 (49.4\%). It is clear that these nurses with A2 level of secondary school do not know or have never learnt anything on the application of nursing theory and the research in nursing. This could explain the fact that these latter do not develop any strategy in their IBP about investigation orient to nursing theory. Therefore, consequences on lack of evidence-based practice will be the lack of improvement in nursing quality enhancing the increasing of morbidity, and mortality of patient. The effectiveness of nursing theories has been associated with a positive attitude, trust and understanding to success in the IBP [8]. The innovation decision process of Roger's model also provides a rationale for this study, as it is essential to explore the knowledge and attitudes of nurses to determine their willingness. The type of nurse theories in evidence-based surveys and its practice in health care settings is an approach to making quality decisions and providing nursing based on personal clinical expertise in combination with the most recent research and the most relevant available on the subject. Moreover, nursing guidance and strategies based on nursing theory is the development of an institutional culture of IBP that is essential to support change in practice [9].

Concerning the prioritization of care, the study revealed that (97.6\%), (96.5\%), (95.3\%) and (15.3\%) were reported as the nurses who are not able to know the systematic collection of information, its priority, prioritizing information during reporting and consideration of patient values respectively (Figure 5). This can be caused by the same mentioned above reasons and will cause the same consequences for patients. However Only $84.7 \%$ argued that they consider the pa- 
tient's preferences and values in decision making or practice based on evidence and clinical expertise. This could be explained by the fact that most of them have been trained in a spiritual way, adding also to the values related to their cultural. However, it cannot explain that the success of IBP could be analyzed. Prioritization allows nurses to identify the most important tasks at any time and give them more attention, energy and time. Additionally, it helps to spend more time on the right things planned [10].

The study showed that the majority of nurses (97.6\%) were not able to plan a rational diagnosis after nursing investigations, Moreover, rational diagnosis was not oriented according to the survey, nor the assessment wasn't considered before confirmation of the diagnosis (Table 2). It is explained by the fact that most of participants did not know the guidelines required during IBP for achieving to the rational diagnosis. This could result to high risk of patient's stay in the hospital, increase of hospital bills for patients and mortality rate. In her study, Ting Ting Lee (2005), suggest that using educational programs for enhancing nurses' ability to use nursing diagnoses and exploring the process of diagnostic reasoning would improve the quality of patient documentation [11].

The study revealed that $76.5 \%, 70.6 \%, 52.9 \%$ were nurses who did not recognize the current analysis in nursing oriented based on evidence respectively with not respecting the stages of information collection, the place of situational analysis and experience in analyzing information (Table 3). It is explained by the fact that participants could not conduct the orientation without knowing the efficiency and efficacy of the finality of each step. This could not make any sense because the protocol was not followed as before for the previous steps. It is also not important because over $97 \%$ of nurses have failed the rational diagnosis. Therefore, if they continue in the same way, nursing care won't be oriented to the IBP and the consequences could be notified for the next steps of nursing care. The nurse's mission is to provide care to patients, to ensure their comfort and well-being in order to maintain or improve their health [12].

This study revealed that majority of participants (76.5\%) know the indicators of patients' satisfaction with nursing interventions through survey-based practice, $74.1 \%$ argued to analyze their information collected (Figure 6). This is explained by the fact that the nurses conduct the IBP without any awareness of what they do and its importance from the first steps until to the end. Therefore, it could be more important to these HCFs to put in place the guidelines, train them on the steps of monitoring and evaluation. "Evaluation is ... gathering a set of relevant, valid and reliable information, and then ... examining the degree of fit between that set of information and a set of appropriately chosen criteria for basing the decision" [13]. Monitoring and evaluation allow nurses to see the quality and impact of their work compared to their action and strategic plans. On the other hands; "monitoring is the systematic collection and analysis of information as a project progresses" [10]. However, only $45.9 \%$ of the participants know the consequences of not following the practice based on a survey. 
A comparative table on participants' knowledge and attitude towards IBP and their Period of experience revealed that only those with $1-4$ years (3.5\%) and 5 9 years $(1.7 \%)$ know the use of theory in nursing and the direction of interventions according to the survey and they were able to know also the importance of IBP (2.4\% and $1.7 \%$ respectively) (Table 4$)$. This concurs the study of Sarah (2017), where she argues that nursing theory should provide the principles that underpin practice and help to generate further nursing knowledge [14]. Moreover, Ingersoll's (2000) definition of evidence-based nursing practice state that "Evidence-based nursing practice is the conscientious, explicit, and judicious use of theory derived research-based information in making decisions about care delivery to individuals or groups of patients and in consideration of individual needs and preferences" [15]. Therefore, this clarifies the importance of using nursing theory into practice (Figure 2). In their study, they argue that nursing theory-guided practice allows the improvement of quality in nursing care because it allows nurses to articulate what they do for patients and why they do it and that is why nurses should continue to guide their nursing practice in line with nursing theories and should continue to evaluate the effectiveness of nursing theory-guided practice [16].

\section{Recommendations}

The following are the recommendations from our study:

- Nurses should apply in their daily activities the research on IBP in other to achieve the outcomes as the main target, create a spirit of interpersonal collaboration, habit of using nursing theories during their practices, informed the steps of monitoring and evaluation during nursing care and prioritize the information collected when treating a patient.

- Healthcare facilities should put in place in-service training for nurses about IBP, promote the nurses with high level for helping other categories during the implementation of IBP skills and establish the guidelines for helping the nurses on how to conduct really the IBP in their daily activities.

- The government/universities should revise the curriculum in other to include the skills related to the IBP so that it helps nurses to conduct the IBP based on the good orientation in other to provide the best rational diagnosis.

\section{Conclusion}

This study revealed a weak awareness on IBP and its importance during nursing practice among participants as for almost all variables, participants were scoring less than $10 \%$, except for the indicators of patients' satisfaction with nursing interventions through survey-based practice (76.5\%). Therefore, in-service training and curriculum revision had been highlighted and recommended in order to provide the best rational diagnosis and achieve the patient's outcomes. 


\section{Limitations}

In our study, the limitations were that it was conducted in two hospitals among the 5 of the one District in which the study was conducted, while the city of Bujumbura has 3 districts. Moreover, this study was conducted in short term of three months (November 2020 to January 2021). Authors did not test the reliability and validity of the questionnaire.

\section{Conflicts of Interest}

The authors declare no conflicts of interest regarding the publication of this paper.

\section{References}

[1] ISTEEBU (2016) Enquête Démographique et de Santé 2016-2017 au Burundi. https://dhsprogram.com/pubs/pdf/SR247/SR247.pdf

[2] Iradukunda, F. and Mayers, P.M. (2020) Rwandan Nursing Students' Knowledge, Attitudes and Application of Evidence-Based Practice. Curationis, 43, a2005. https://doi.org/10.4102/curationis.v43i1.2005

[3] Melnyk, B., Fineout-Overholt, E., Gallagher-Ford, L. and Stillwell, S. (2011) Evidence-Based Practice, Step by Step: Sustaining Evidence-Based Practice through Organizational Policies and an Innovative Model. American Journal of Nursing, 111, 57-60. https://pubmed.ncbi.nlm.nih.gov/21865934 https://doi.org/10.1097/01.NAJ.0000405063.97774.0e

[4] Goode, C.J. (2013) Evidence-Based Clinical Practice. The Journal of Nursing Administration, 29, 15-21. https://europepmc.org/article/med/10377921

[5] Dufault, M.A. (2001) A Program of Research Evaluating the Effects of a Collaborative Research Utilization Model. Worldviews Evidence-Based Nursing, E8, 37-43. https://doi.org/10.1111/j.1524-475X.2001.00037.x

[6] Beverly, A., Walter, E. and Carraretto, M. (2016) Evidence-Based Practice and Research Utilization Activities among Rural Nurses. American Nurses Publishing, Washington DC.

[7] Badoer, E. (2010) Evidence-Based Practice: A Practical Approach to Implementation. Acta Psychiatrica Scandinavica, New York.

[8] McSherry, R., Angela, A. and Holloran, J. (2006) Research Awareness: An Important Factor for Evidence-Based Practice? Worldviews on Evidence-Based Nursing, 3, 103-115. https://doi.org/10.1111/j.1741-6787.2006.00059.x

[9] Jin, Q., Chen, E., et al. (2012) Evidence-Based Practice. Johns Hopkins University Press, New York.

[10] Heled, Y., Fleischmann, C. and Epstein, Y. (2013) Cytokines and Their Role in Hyperthermia and Heat Stroke. Journal of Basic and Clinical Physiology and Pharmacology, 24, 85-96. https://doi.org/10.1515/jbcpp-2012-0040

[11] Lee, T. (2005) Nursing Diagnoses: Factors Affecting Their Use in Charting Standardized Care Plans. Journal of Clinical Nursing, 14, 640-647.

https://doi.org/10.1111/j.1365-2702.2004.00909.x

[12] Steven, D. (2017) Inquiry Evidence Practice. 9th Edition.

[13] Hildebrandt, B., Wust, P., et al. (2002) A Framework for the Dissemination and Utilization of Research for Health-Care Policy and Practice. The Mosby Company, 
Toronto.

[14] Sarah, C. (2017) Nursing Theory: Its Importance to Practice.

https://journals.rcni.com/nursing-standard/nursing-theory-its-importance-to-pract ice-ns2003.07.17.46.33.c3425\#: :text=The\%20importance $\% 20$ of $\% 20$ nursing\%20the ory\&text $=$ The $\% 20$ benefits $\% 20$ of $\% 20$ having $\% 20$ a, and $\% 20$ education $\% 20$ (Nolan $\% 20$ 1996)

[15] Fawcett, J., Watson, J., Neuman, B., Walker, P. and Joyce, J. (2001) On Nursing Theories and Evidence. Journal of Nursing Scholarship, 33, 115-119. https://doi.org/10.1111/j.1547-5069.2001.00115.x

[16] Younas, A. and Quennell, S. (2019) Usefulness of Nursing Theory-Guided Practice: An Integrative Review. Scandinavian Journal of Caring Sciences, 33, 540-555.

https://www.researchgate.net/publication/331723163_Usefulness_of_nursing_theor y-guided_practice_an_integrative_review 